\title{
Study on the Environmental Management Countermeasures in the Whole Process of Low-Grade Highway Construction
}

\author{
Deqin Ran and Chengcheng Li \\ Shandong Transportation Institute, 250102, 1877 Gangxi Road, Licheng District, \\ Jinan City, Shandong Province, China \\ randeqin@126.com
}

\begin{abstract}
As an important link between urban and rural areas, low-grade highway bears the dual functions of internal distribution traffic and transit traffic. At the same time, low-grade highway also has problems such as complex traffic composition, weak infrastructure and so on. Its environmental protection management ratio is relatively weak in the whole process of construction, which brings many environmental problems and affects ecological benefits. In order to reduce the impact of low-grade highway construction on the surrounding township environment during the construction period and maintain the integrity of the surrounding ecological environment, it is necessary to pay more attention to the environmental problems during the construction period. This paper studies and analyzes the framework system of environmental protection management in the construction period of low-grade highway. Combined with the requirements of environmental protection management in the construction period of highway, it expounds the impact of the construction period of highway on the environment, the existing problems and current situation of environmental protection management, introduces the contents of environmental protection management, and analyzes the framework system of environmental protection management. Based on this, this paper analyzes the impact of low-grade highway construction on the ecological environment, and puts forward the corresponding countermeasures.
\end{abstract}

Keywords: Environmental management, Countermeasures, Whole process, Lowgrade highway

\section{Introduction}

Traffic is the lifeblood of economic development, low-grade highway is an important part of the road network, and is one of the most important infrastructure to ensure the economic and social development of rural areas [1]. However, in the actual construction process, the highway project mainly considers the influence of time limit, cost and quality, thus neglecting the negative impact of the construction project on the surrounding environment. As the environment is a difficult target to quantify, and based on the weak technical and institutional foundation of environmental management in China, this paper comprehensively analyzes the environmental protection management framework system, which provides comprehensive support and guarantee for the environmental protection during the construction of low-grade highway, and is conducive to the coordination and unification of economic benefits, social

Article history:

Received (January 8, 2020), Review Result (February 14, 2020), Accepted (April 6, 2020) 
benefits and environmental benefits of highway construction projects. The implementation of environmental protection measures in the process of highway construction is the basic requirement for the implementation of green highway construction. However, highway construction is a long period and a large amount of construction projects. In the process of highway construction, it often causes certain damage to the local natural environment, causes different degrees of pollution and damage to the local terrain, landform, water resources, air, etc., and seriously affects people's normal life [2]. Therefore, in the process of highway construction, corresponding protection measures should be taken to reduce the damage and impact of highway construction on the surrounding ecological environment.

\section{Analysis of the environmental impact of the construction period of the low-grade highway}

\subsection{Air pollution}

Highway construction is a long-term and large-scale project, which has many effects on the air in the construction process, mainly in the following aspects: first, a large amount of dust will be generated in the process of subgrade excavation and backfilling; second, a large number of raw materials will be used in the construction process, such as lime, fly ash, steel bar, sandstone, cement, asphalt, etc In the process of loading, unloading, transportation and mixing, a lot of dust will be generated, which will cause environmental pollution [3]. At the same time, some chemical reactions will be generated after mixing, which will release harmful gases, thus affecting the air quality and causing environmental pollution. Thirdly, due to the confusion of construction site management, the waste raw materials cannot be properly treated, and cannot be disposed or transported as soon as possible. A large number of waste raw materials are stacked in the Roadside, not only causes the waste of raw materials, but also has a certain impact on the construction. The wind will also produce a lot of dust, which will reduce the air quality; fourth, a lot of mechanical equipment will be used in the construction process, which will produce a lot of tail gas, such as carbon monoxide, nitric oxide and other harmful gases, resulting in air pollution. To sum up, due to a large number of dust, dust and harmful gas emissions, not only the local air quality will decline, resulting in haze and other bad weather, but also the human health will be affected to a certain extent, as well as the construction.

\subsection{Water pollution}

The impact of road construction on water resources is various, mainly in the following aspects: first, the pollution caused by the random discharge of construction domestic wastewater and sewage to the river; second, the bridge construction needs drilling, piling and other technologies, which will produce a lot of mud, drilling slag and other wastes in the process of drilling and piling construction, which will fall into the river, causing water pollution; construction during the construction process, a large number of construction raw materials are stacked randomly, such as asphalt, cement, chemicals, etc. after a long time of wind blowing, rain washing, infiltration, etc., it will cause certain impact and pollution to the surface water resources; during the construction process, the mixing and maintenance of cement concrete and the cleaning of construction machinery will also cause certain pollution to the water resources [4]. The pollution of water resources will not only seriously affect people's life health, bring great inconvenience to people's life, but also affect local fishery and planting industry. Therefore, in the process of highway construction, the protection of water 
resources must be given high attention, which is related to people's health and ecological development.

\subsection{Soil erosion}

In the process of highway construction, the section forms of subgrade mainly include embankment, cutting, half filling and half digging, so subgrade excavation, subgrade backfilling and soft soil foundation treatment are common construction processes in the process of highway construction. In the process of subgrade excavation or backfilling, the construction personnel often do not take the original surface vegetation into account, and directly excavate or backfill, which causes serious damage to the surface vegetation, changes the soil structure, and reduces the protection ability of the surface soil layer. If encountering rain weather, it is easy to cause landslides, thus causing water and soil loss [5]. In addition, during the excavation process, the excavated earthwork will be used for Subgrade Backfilling on the one hand. In addition, in order to save time and labor, the redundant construction units may stack on both sides of the road at will. After a series of construction processes such as excavation, the density of the earthwork has been reduced and become loose. If encountering storm and heavy rain at this time, it is easy to cause landslide and water and soil loss. At the same time, the drainage ditch on both sides of the road and the slope protection on both sides of the road mainly include masonry protection and grass planting protection. If the construction is not in place, it will indirectly cause soil erosion. The water and soil loss caused by the road construction will not only bring inconvenience to the local people's life, but also affect the local agriculture, forestry, etc., and cause irreversible impact on the local ecological environment.

\section{Countermeasures of environmental management problems in the construction period of low-grade highway}

\subsection{Countermeasures of air pollution}

In order to reduce the air pollution caused by the dust generated during the transportation of raw materials, certain covers can be used to cover the air during the transportation, and the raw materials can be properly humidified without affecting the use quality of the raw materials; the waste raw materials generated during the construction shall be transported to the outside of the construction site in time and treated in accordance with the relevant regulations to ensure the waste raw materials Under the premise that the materials are not harmful, they can be used for subgrade filling of rural roads, so as to achieve the secondary use of waste materials [6]. Waste raw materials shall not be piled up for a long time to prevent chemical reaction caused by long-term weathering, rainwater and other effects and release of harmful gases; a large number of machinery and equipment will be used in the construction process, and the construction party shall try to select new environmental protection machinery and equipment to reduce the exhaust emission of machinery and equipment; in the process of subgrade excavation and backfilling, the operation under strong wind environment shall be avoided as far as possible, Water spraying shall be properly adopted to reduce the impact of dust on the environment.

\subsection{Countermeasures of water pollution}


It is strictly prohibited to discharge construction domestic wastewater and sewage directly into the river, and corresponding drainage measures shall be set up to discharge them uniformly after centralized sewage reduction treatment; mud purification equipment shall be used for the treatment of mud and drilling slag generated in the construction process, and corresponding sedimentation tank shall be set up; the mixing of cement concrete and mechanical cleaning shall be far away from the residential area during the construction process As well as corresponding rivers, fences shall be set around them. It is strictly prohibited to directly discharge the mixed sewage [7]. Sedimentation tanks shall be set reasonably, and discharge shall be carried out after unified sewage reduction. Building materials shall be stacked in a unified way. During the storage process, certain films shall be laid on the storage site, and some covers shall be placed on the upper part of the materials to avoid chemical reaction caused by wind, sun or rain erosion, and the materials shall flow into the river Pollution of water for planting and people's living. Pay full attention to the pollution caused by water resources in the construction process. If necessary, an environmental supervision team can be set up to inspect the construction site at any time, report the existing environmental problems to solve them in time, and minimize the pollution of water resources from the source.

\subsection{Countermeasures of soil erosion}

First of all, in the stage of highway design and route selection, it is necessary to reduce the occupation of agricultural land, try to choose flat land and avoid mountains with high and low fluctuation. Subgrade backfilling and excavation are essential construction procedures for highway construction. In the process of excavation and backfilling, the buried damage to surrounding plants shall be reduced as much as possible to reduce the change of soil structure; for a large amount of earth and stone produced by excavation, except for filling, the excess earth and stone shall be strictly prohibited to pile up on site, causing damage to surrounding plants, and used to sort the subgrade slope as much as possible, and Properly increase the greening plants, increase the protection ability to the surface, and reduce the probability of water and soil loss; when the waste earth and stone are piled up, they should not be too high, and the waste earth and stone are relatively loose, which is easy to collapse in rainy days and cause water and soil loss [8]. In order to reduce the probability of water and soil loss, corresponding drainage works and soil protection works shall be set up according to the needs during the construction process, the greening on both sides of the road shall be strengthened as much as possible, the soil for road land shall be solidified, and the probability of water and soil loss shall be reduced.

\section{Current situation and existing problems of environmental management in the construction period of low-grade highway}

In recent years, with the gradual promotion of China's sustainable development strategy, more and more attention has been paid to environmental protection and management at the national level. The environmental protection assessment during the construction period of highway is mainly to predict the environmental impact during the construction process and then issue the relevant environmental assessment report. Highway construction is a dynamic and mostly involved project. Before construction, the design unit will provide relevant construction drawings. Although the site survey has been conducted before the construction drawing design, due to the complexity and uncertainty of geological landform, design changes and construction scheme and technology changes often occur in the construction 
process, which results in the previous project construction The impact on the environment is inconsistent with the current impact, and there is a certain difference between the EIA report and the actual environmental impact.

In addition, some experts in charge of environmental impact assessment are not familiar with the project due to fewer visits to the construction site. In addition, these review experts are not independent of the problem review of project construction, which can easily cause public doubts about the results of environmental impact assessment [9]. Secondly, highway drawing designers prefer to design. In the design process, not only the construction problems but also the cost problems are considered, and then the environmental problems are not considered enough. There is a lack of professional environmental protection designers. Construction drawing designers are not equal to environmental protection designers, and lack of relevant environmental design expertise. In addition, the highway is the most infrastructure connecting all places, with the characteristics of long mileage and large crossing area. A highway may pass through multiple complex terrains such as flat land, hills and mountains, which requires different terrain to require different environmental management measures and different environmental assessment reports. In view of the weakness of the current environmental protection management system, it is often inconsistent with the actual construction area Furthermore, it shows that the quality of EIA report of construction project is not high and its practicability is poor. Of course, some local governments neglect the environmental management of construction projects, which results in that the managers of construction projects of some construction units only value the economic interests of their own enterprises, lack of social responsibility, weak concept of environmental legal system, and ignore the environmental protection management system measures.

\section{Construction of environmental protection management framework system in the construction period of low-grade highway}

The framework system of environmental protection management has standardized operation documents, which is a structured dynamic management body for the purpose of protecting the ecological environment. It provides scientific and effective guidance and comprehensive guarantee for the environmental management of construction projects, so as to promote the development and progress of China's environmental management, improve the whole management system of construction projects, and achieve environmental, social and Unified and coordinated development of economic benefits of the project.

\subsection{Environmental protection management framework system and regulatory framework}

The environmental protection management framework system of highway construction project is established on the basis of the environmental laws and regulations as well as the existing problems and current situation of environmental management [10]. On the basis of relevant environmental laws and regulations, systems and standards, the advantages and disadvantages of the system are analyzed carefully, and advanced practical experience at home and abroad is used for reference, so as to establish a set of system suitable for China's current environmental protection management. The establishment of the system will provide China's environmental protection management with legal, standardized and institutionalized management, as well as China's current environmental protection management the problems in nursing management can provide comprehensive guidance, which will play a positive role in promoting the improvement and development of environmental management in China. 


\subsection{Technical method system of environmental protection management framework}

From the perspective of management, the technical method system of environmental protection management should be established. The establishment of this method requires comprehensive analysis of different construction projects, different construction schemes and regions, different management requirements and the damage and impact on the environment at the same time [11]. On the basis of the existing technical methods of environmental management of construction projects, it is necessary to improve and enhance the highway environment The effectiveness of methods such as protection design, environmental supervision and environmental completion acceptance can provide strong technical support for environmental protection of highway construction projects in China, implement various measures for environmental protection of highway construction projects, and control the impact and damage of construction projects on the environment from the source.

\subsection{Environmental protection management framework information system}

Scientific, efficient and standardized environmental management of construction projects is inseparable from the establishment of environmental protection management information system. The establishment of this information system can not only combine the information needed for environmental management in each stage of the project, but also analyze each stage of the project, thus establishing data information management database and environmental monitoring platform, which can provide information for environmental protection management of construction projects It can provide technical guidance, check and supervise the progress of environmental protection of construction projects at any time, and improve the timeliness of environmental protection management of construction projects.

\section{Conclusion}

Low-grade highway brings convenience to people's life and travel, and it may cause continuous and irreversible impact on the environment of villages and towns in the construction process. Therefore, we should take corresponding measures to develop effective environmental management in the construction period of low-grade highway, and minimize the impact of the construction of low-grade highway on surrounding towns and villages in the construction period the impact of the environment, to maintain the integrity of the surrounding ecological environment.

The construction of environmental protection management framework system during the construction period of low-level highway not only improves the existing environmental protection management system and laws and regulations, but also provides technical support and guidance for low-level highway construction projects in China, thus improving the effectiveness and practicality of environmental protection management, promoting the development of environmental protection management of low-level highway construction projects in China, and realizing the public Road construction projects have played an irreplaceable role in the coordinated development of economic, social and environmental benefits.

\section{Acknowledgements}

The authors are grateful for financial support by Shandong province local road network traffic construction standardization demonstration and intelligent promotion demonstration 
construction project (C1940, research on environmental management countermeasures in the whole process of low-grade highway construction). The contributions of the manuscript reviewers is also acknowledged.

\section{References}

[1] Beljatynskij A, Kuzhel N, and Prentkovskis O, et al., "The criteria describing the need for highway reconstruction based on the theory of traffic flows and repay time," Transport, vol.24, no.4, pp.308-317, (2009)

[2] Xu Sheng Guo, Qu Jin Feng, and Dong Fang Qing, et al., "Analysis of the construction of qilihai south pumping station's ecological and environmental impact on qilihai wetland," Applied Mechanics \& Materials, pp.744-746, (2015)

[3] N. Barikayeva, D. Nikolenko, and J. Ivanova, "About forecasting air pollution in the construction of highways," IOP Conference Series Materials Science and Engineering, vol.463, pp.042016, (2018)

[4] N. I. Koronkevich, E. A. Barabanova, and A. G. Georgiadi, et al, "Anthropogenic impacts on the water resources of the russian arctic basin rivers, Geography and Natural Resources, vol.40, no.1, pp.22-29, (2019)

[5] Zech W C, Halverson J L, and Clement T P, "Intermediate-scale experiments to evaluate silt fence designs to control sediment discharge from highway construction sites,” Journal of Hydrologic Engineering, vol.13, no.6, pp.497-504, (2008)

[6] Wenkang Gao, Guiqian Tang, and Dongsheng Ji, et al., "Implementation effects and countermeasures of China's air pollution prevention and control action plan," Research of Environmental Sciences, vol.29, no.11, pp.1567-1574, (2016)

[7] Li J, Zhang J, and Xiao L, et al., "The design countermeasures of embankment of Mohe-Beijicun Highway in permafrost regions," International Conference on Remote Sensing. IEEE, (2011)

[8] S. Liu, "Principle, strategy and methods of geological route line selection in highway engineering design," Journal of Chengdu University of Technology, vol.44, no.4, pp.417-424, (2017)

[9] Ashwani Sharma, "Environmental management framework of persistent organic pollutants in India: Existing scenario and prospects," Management of Environmental Quality an International Journal, vol.25, no.6, pp.3942, (2014)

[10] Warren Karlenzig, "The computers and electronics industry alternative system of environmental protection: A new pilot program,” Environmental Quality Management, vol.6, no.3, pp.29-32, (2006)

[11] C.W. Young and R.J. Welford, "An environmental performance measurement framework for business," Greener Management International, vol.21, no.21, pp.30-49, (1998)

[12] H. W. Chen, R. F. Yu, and S. L. Liaw, et al., "Information policy and management framework for environmental protection organization with ecosystem conception," International Journal of Environmental Science \& Technology, vol.7, no.2, pp.313-326, (2010) 
Study on the Environmental Management Countermeasures in the Whole Process of Low-Grade Highway Construction

This page is empty by intention. 